\title{
Efecto del aditivo probiótico Lactobacillus pentosus LB-31 en pollos de ceba
}

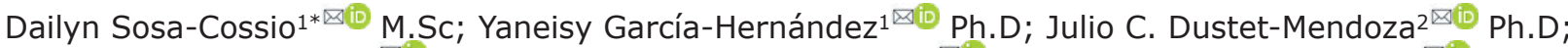

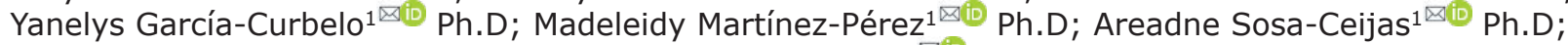 \\ Dayron García-Quiñones ${ }^{1 凶(\mathbb{E}}$ M.Sc.
}

\begin{abstract}
${ }^{1}$ Instituto de Ciencia Animal (ICA). Carretera Central km 47 1/2 San José de las Lajas, C.P. 32700, Apartado Postal 24, Mayabeque, Cuba.

2Universidad Tecnológica de La Habana "José Antonio Echeverría" (CUJAE), Facultad de Ingeniería Química. Ave. 114 No. 11901 entre Ciclovía y Rotonda, Marianao, La Habana, Cuba.

*Correspondencia: dsosa@ica.co.cu
\end{abstract}

Recibido: May 2020; Aceptado: Agosto 2020; Publicado: Diciembre 2020.

\section{RESUMEN}

Objetivo. Determinar la respuesta biológica de pollos de ceba al incluir en la dieta el aditivo probiótico Lactobacillus pentosus LB-31, que se obtuvo en un medio de cultivo económico y diferentes condiciones de producción. Materiales y métodos. Se utilizó diseño completamente aleatorizado con ocho animales por tratamiento. Se establecieron dos grupos experimentales: el primero consumió la dieta basal sin antibióticos (grupo control) y el segundo la dieta basal con la adición de Lactobacillus pentosus LB-31 en concentración de $10^{7}$ ufc/g de alimento. Se determinaron indicadores hematológicos, de bioquímica sanguínea, morfométricos e inmunológicos. Resultados. A los 42 días de edad de los animales no se encontraron diferencias entre tratamientos para la hemoglobina y hematocrito. La relación albúmina/globulinas y los niveles de albúmina, colinesterasa y glutatión aumentaron $(p<0.05)$; mientras que las concentraciones de globulinas, ácido úrico, amilasa pancreática, fosfatasa alcalina, colesterol y triglicéridos disminuyeron $(p<0.05)$ con la inclusión de LB-31 en la dieta de los animales. En los indicadores morfométricos el probiótico solo tuvo efecto $(p<0.05)$ en el peso relativo $(\mathrm{g} / \mathrm{kg}$ de peso vivo) del intestino delgado que disminuyó y la grasa abdominal que aumentó. Conclusiones. Lactobacillus pentosus LB-31, cultivado en un nuevo medio de cultivo y diferentes condiciones de obtención, mantiene su actividad probiótica en indicadores morfo-fisiológicos y bioquímica sanguínea de pollos de ceba.

Palabras clave: Actividad probiótica; bacteria ácido láctica; salud animal (Fuente: MeSH, DeCS).

\section{ABSTRACT}

Objective. Determine the biological response of broilers by including the probiotic additive Lactobacillus pentosus LB-31 in the diet, which was obtained in an economical culture medium and under different production conditions. Materials and methods. A completely randomized design was used with eight animals per treatment. Two experimental groups were established: the first consumed the basal diet without antibiotics (control group) and the second the basal diet with the 
addition of Lactobacillus pentosus LB-31 in a concentration of $10^{7} \mathrm{cfu} / \mathrm{g}$ of food. Hematological, blood biochemical, morphometric and immunological indicators were determined. Results. At 42 days of age of the animals, there was no difference among treatments for hemoglobin and hematocrit. Albumin/globulin relation and albumin, cholinesterase and glutathione levels increased $(p<0.05)$ while concentrations of globulins, uric acid, pancreatic amylase, alkaline phosphatase, cholesterol and triglycerides decreased $(p<0.05)$ with the inclusion of LB-31 in the diet. In the morphometric indicators, the probiotic only had an effect $(p<0.05)$ on relative weight $(\mathrm{g} / \mathrm{kg}$ of live weight) of small intestine that decreased and the abdominal fat that increased. Conclusions. Lactobacillus pentosus LB-31, cultivated in a new culture medium and under different production conditions, maintains its probiotic activity in morpho-physiological and blood biochemistry indicators of broilers.

Keywords: Probiotic activity; lactic acid bacteria; animal health (Source: MeSH, DeCS).

\section{INTRODUCCIÓN}

La alimentación y el manejo de los animales son los factores que más pueden influir en la manipulación del ecosistema gastrointestinal de las aves (1). El empleo de probióticos es una de las alternativas de interés para incidir en este ambiente, ya que son aditivos dietéticos formados por microorganismos vivos que tienen un efecto beneficioso en la salud del hospedero (2). Generalmente, la aplicación de estos aditivos en la producción animal se relaciona con la estabilización y protección del ecosistema gastrointestinal, mejoras en los procesos metabólicos y digestivos, así como la modulación del sistema inmune. Estos efectos pueden incrementar los rendimientos productivos $y$, por ende, la disponibilidad y calidad de la carne y huevos destinados a la población (1).

Los microorganismos más utilizados como probióticos son cepas de los géneros Lactobacillus, Bifidobacterium, Bacillus, Enterococcus y levaduras (3). La selección de la cepa o cepas microbianas es el primer paso para la concepción de un producto probiótico. Estos deben ser microorganismos Generalmente Reconocidos como Seguros (GRAS, por sus siglas en inglés), capaces de sobrevivir en el tracto gastrointestinal (TGI) y tolerar $\mathrm{pH}$ bajos y altas concentraciones de sales biliares (4). Otras características requeridas son la capacidad de adherencia de las cepas probióticas al epitelio intestinal para su posterior colonización (5), ser microorganismos estables genéticamente y poseer altas velocidades de crecimiento. Además, la cepa seleccionada debe mantener su viabilidad y actividad probiótica durante los procesos de fabricación, transporte y almacenamiento (6).

La FAO/WHO (2) sugirieron que los probióticos deben tener una concentración mínima de $10^{6}$
$10^{7}$ células/mL o g de producto para garantizar su eficacia. Sin embargo, no existe ninguna otra metodología o guía que esclarezca cuáles deberían ser las dosis a emplear según las categorías o especie animal. Específicamente, en pollos de ceba se utilizan diferentes dosis, por ejemplo Bai et al (7) evaluaron una concentración de $10^{7} \mathrm{ufc} / \mathrm{g}$ de una cepa de Lactobacillus fermentum, mientras que Kazemi et al (8) utilizaron un probiótico multiespecie comercial con una concentración mínima de $10^{9} \mathrm{ufc} / \mathrm{g}$ de producto. Asimismo, se deben considerar otros aspectos que pueden influir en la respuesta probiótica como la frecuencia y modo de aplicación del aditivo, edad y estado fisiológico del hospedero.

Lactobacillus pentosus LB-31 es una cepa de origen aviar, aislada de excretas fermentadas de pollos de ceba, que en ensayos in vitro mostró las mayores potencialidades probióticas (1). LB-31 es un microorganismo GRAS que demostró, además, que no afectaba la salud animal a través de estudios de toxicidad aguda en ratas de laboratorio. Por otra parte, su acción benéfica se confirmó en pollos de ceba (1) en una concentración de $10^{8} \mathrm{ufc} / \mathrm{g}$ de alimento. También se evaluó en truchas arco iris (9), cerdos en crecimiento (10) y corderos pelibuey (11).

Las investigaciones anteriores se realizaron cultivando LB-31 en caldo MRS (De Man-RogosaSharpe) y pequeños volúmenes de fermentación en erlenmeyers de laboratorio. La utilización de este medio de cultivo no es factible a nivel industrial por la complejidad de su composición y sus altos precios en el mercado (12). Surge, entonces, la necesidad de utilizar otras fuentes de nutrientes económicas como la melaza de caña de azúcar para la producción de biomasa probiótica a escalas productivas. Además, se plantea que los procesos de producción y 
fabricación pueden influir en las propiedades de las cepas probióticas y tener impacto en sus resultados (13). Por estas razones es necesario comprobar la respuesta biológica de los animales al consumir el aditivo con LB-31 en cada una de las escalas que se estudien para su producción a nivel industrial. De ahí que la presente investigación tuvo como objetivo determinar la respuesta biológica de pollos de ceba al incluir en la dieta el aditivo probiótico Lactobacillus pentosus LB-31, que se obtuvo en un medio de cultivo económico y diferentes condiciones de producción.

\section{MATERIALES Y MÉTODOS}

Área de estudio. El trabajo experimental se desarrolló en la unidad avícola del Instituto de Ciencia Animal. Este centro se encuentra situado en el km $471 / 2$ de la Carretera Central, a 220 53' de latitud norte, $82^{\circ} 02^{\prime}$ de longitud oeste y 92 m.s.n.m, en el municipio San José de las Lajas, provincia Mayabeque, Cuba.

Animales y dieta basal. Se emplearon 16 pollos de ceba machos del híbrido EB-34 de un día de edad con peso promedio inicial de $40 \pm 2 \mathrm{~g}$, que se alojaron en jaulas metálicas hasta los 42 días. Los animales consumieron, a voluntad, agua y una dieta a base de maíz y soya. Esta última se elaboró en la fábrica de piensos del Instituto de Ciencia Animal, según los requerimientos establecidos por el Instituto Avícola de Cuba, y varió en su composición para inicio, crecimiento y acabado (Tabla 1 ).

Microorganismo y preparación del aditivo probiótico. Se utilizó la cepa Lactobacillus pentosus (LB-31) perteneciente al Banco de Microorganismos para la Producción Animal (BAMIPA) del Instituto de Ciencia Animal (Mayabeque, Cuba). LB-31 se identificó por secuenciación del gen 165 ARN ribosomal y su secuencia se encuentra depositada en el GenBank con número de acceso: FR717464 (1). Para la presente investigación el probiótico se obtuvo a partir de un lote de fermentación. Se utilizaron $20 \mathrm{~mL}$ de la cepa activada en caldo MRS (Oxoid, UK) a $37^{\circ} \mathrm{C}$ y $24 \mathrm{~h}$ de incubación para obtener el inóculo a estas mismas condiciones. En el proceso fermentativo se empleó un biorreactor (BIONET, España) de $11 \mathrm{~L}$ con volumen efectivo de $8 \mathrm{~L}$ de un medio de cultivo diseñado con melaza de caña de azúcar, urea y otras sales, aspectos que constituyen objeto de una posible solicitud de patente cubana. El aditivo tuvo una concentración de $10^{8} \mathrm{ufc} / \mathrm{mL}$ y se conservó a $4 \pm 2^{\circ} \mathrm{C}$ en frascos estériles de $500 \mathrm{~mL}$ durante toda la etapa experimental.

Tabla 1. Composición de la dieta para pollos de ceba por etapa de crecimiento

\begin{tabular}{|c|c|c|c|}
\hline $\begin{array}{c}\text { Ingredientes } \\
\text { (\% en base seca) }\end{array}$ & $\begin{array}{l}\text { Inicio } \\
(0-21 \mathrm{~d})\end{array}$ & $\begin{array}{c}\text { Crecimiento } \\
(22-35 \mathrm{~d})\end{array}$ & $\begin{array}{l}\text { Acabado } \\
(36-42 \mathrm{~d})\end{array}$ \\
\hline Harina de maíz & 47.00 & 52.90 & 58.79 \\
\hline Harina de soya & 41.13 & 35.87 & 30.40 \\
\hline Aceite vegetal & 6.60 & 6.30 & 6.00 \\
\hline Carbonato de calcio & 1.50 & 1.50 & 1.40 \\
\hline Fosfato monocálcico & 1.80 & 1.60 & 1.60 \\
\hline $\begin{array}{l}\text { Premezcla minero- } \\
\text { vitamínica* }\end{array}$ & 1.00 & 1.00 & 1.00 \\
\hline Cloruro de colina & 0.13 & 0.13 & 0.13 \\
\hline Sal común & 0.35 & 0.33 & 0.33 \\
\hline DL- Metionina & 0.31 & 0.25 & 0.24 \\
\hline Lisina & 0.18 & 0.12 & 0.11 \\
\hline \multicolumn{4}{|c|}{ Aportes calculados } \\
\hline Proteína bruta (\%) & 23.00 & 20.00 & 18.50 \\
\hline EM $\left(M J \cdot \mathrm{kg}^{-1}\right)$ & 13.00 & 13.39 & 13.39 \\
\hline Fósforo disponible (\%) & 0.40 & 0.45 & 0.45 \\
\hline Calcio (\%) & 0.95 & 0.95 & 0.95 \\
\hline Metionina+Cistina (\%) & 0.90 & 0.85 & 0.80 \\
\hline Lisina (\%) & 1.34 & 1.13 & 1.01 \\
\hline Treonina (\%) & 0.99 & 0.85 & 0.79 \\
\hline Triptófano (\%) & 0.35 & 0.26 & 0.23 \\
\hline
\end{tabular}

*Premezcla mineral por kg de alimento: selenio $(0.1$ $\mathrm{mg})$, hierro $(40 \mathrm{mg})$, cobre $(12 \mathrm{mg})$, zinc $(120 \mathrm{mg})$, magnesio $(100 \mathrm{mg})$, yodo $(2.5 \mathrm{mg})$ y cobalto $(0.75 \mathrm{mg})$ y Premezcla vitamínica por kg de alimento: vitamina $A$ (10 $000 \mathrm{UI})$, vitamina D3 (2 $000 \mathrm{UI})$, vitamina E (10 mg), vitamina K3 (2 mg), vitamina B1 (tiamina, $1 \mathrm{mg}$ ), vitamina B2 (riboflavina, $5 \mathrm{mg}$ ), vitamina B6 (piridoxina, $2 \mathrm{mg}$ ), vitamina B12 (cianocobalamina, $15.4 \mathrm{mg}$ ), ácido nicotínico $(125 \mathrm{mg})$, pantotenato de calcio $(10 \mathrm{mg})$, ácido fólico $(0.25$ $\mathrm{mg}$ ) y biotina $(0.02 \mathrm{mg})$.

Tratamientos. Se establecieron dos grupos experimentales que consumieron: 1) dieta basal sin antibióticos (grupo control) y 2) dieta basal con la adición de Lactobacillus pentosus LB-31 en dosis de $100 \mathrm{~mL} / \mathrm{kg}$ de alimento, equivalente a $10^{7} \mathrm{ufc} / \mathrm{g}$ de alimento, según lo recomendado por la FAO/WHO (2) El aditivo se mezcló, diariamente, de forma manual con la dieta basal.

Condiciones experimentales y sistema de manejo de los animales. Previamente, se realizó la habilitación sanitaria de la nave según los protocolos establecidos por el Instituto Avícola de Cuba, para el manejo de pollos de ceba. El agua se ofreció en bebederos de tipo tetinas y la dieta basal se suministró en comederos lineales, los que se ajustaron al tamaño de los pollos durante la crianza. La iluminación de la nave durante el experimento fue de 24 h, 12 h de 
Iuz natural y $12 \mathrm{~h}$ de luz artificial. El sistema de vacunación de los animales consistió en una dosis de Marek, viruela aviar, bronquitis infecciosa al primer día de nacidos los pollos, Gumboro a los 1,7 y $21 \mathrm{~d}$ y la vacuna de Newcastle a los $14 \mathrm{~d}$.

Procedimiento experimental para la toma y análisis de las muestras. A los 42 días de edad, se pesaron individualmente ocho animales por tratamiento y se sacrificaron por desangrado de la vena yugular. Se tomaron muestras de $1 \mathrm{~mL}$ de sangre en tubos con y sin heparina sódica. Posteriormente, se abrió la cavidad abdominal y se extrajeron los órganos accesorios $y$ el tubo digestivo. Las potencialidades del aditivo probiótico se determinaron en función de indicadores hematológicos, de bioquímica sanguínea, morfométricos e inmunológicos.

Como indicadores hematológicos se midió la hemoglobina por el método de la cianometahemoglobina descrito por Crosby et al (14) y el hematocrito que se determinó mediante microcentrifugación a $10000 \mathrm{~min}^{-1}$ durante 5 min. La lectura de los sedimentos hemáticos se realizó mediante un lector para microhematocrito marca Hawkley. Después de someter la sangre a coagulación a temperatura ambiente $\left(26 \pm 2^{\circ} \mathrm{C}\right)$, se centrifugó a $3500 \mathrm{~min}^{-1}$ durante $15 \mathrm{~min}$ con el objetivo de obtener los sueros para determinar los indicadores de bioquímica sanguínea (proteínas totales, relación albúmina/ globulinas, albúmina, globulinas, ácido úrico, alanino aminotransferasa (ALAT), aspartato aminotransferasa (ASAT), glucosa, amilasa pancreática, fosfatasa alcalina, colinesterasa, glutatión, colesterol y triglicéridios) en un analizador automático Cobas Integra 400 PLUS (Roche Diagnostic Sistem).

Los indicadores morfométricos e inmunológicos se expresaron, para su análisis estadístico, como relativos al peso vivo ( $\mathrm{g} / \mathrm{kg}$ de peso vivo). En el primer caso se pesó el buche, proventrículo, molleja, intestino delgado, ciegos y colon-recto vacíos, hígado, páncreas y grasa abdominal. Mientras que en el segundo se pesaron los órganos relacionados con el sistema inmune: timo y bolsa de Fabricio. Para ello se utilizó una balanza técnica Sartorius BL 1500.

Diseño experimental y análisis estadístico. Se utilizó diseño completamente aleatorizado, donde los animales se distribuyeron de forma individual en jaulas de metabolismo. Se utilizaron ocho animales por tratamientos y cada uno constituyó una unidad experimental. Los datos experimentales se procesaron con el paquete estadístico Infostat (15).

\section{RESULTADOS}

En la presente investigación, la inclusión de Lactobacillus pentosus LB-31 en la dieta de los pollos de ceba no tuvo efecto en los indicadores hematológicos. Se obtuvieron valores de hemoglobina de 10.46 y $10.50 \mathrm{~g} / \mathrm{dL}(\mathrm{EE} \pm 0.13$; $\mathrm{p}=0.8302$ ) y de hematocrito de 31.38 y $31.50 \%$ $(E E \pm 0.04 ; p=0.8281)$ para el tratamiento control y el probiótico, respectivamente.

En la tabla 2 se muestran los resultados de los indicadores de bioquímica sanguínea. Se encontró que la relación albúmina/globulina y las concentraciones de albúmina, colinesterasa y glutatión aumentaron $(p<0.05)$; mientras que los niveles de globulinas, ácido úrico, amilasa pancreática, fosfatasa alcalina, colesterol y triglicéridos disminuyeron $(p<0.05)$ cuando los animales consumieron $L$. pentosus LB-31 en la dieta. El resto de los indicadores (proteínas totales, enzimas ALAT y ASAT y glucosa) no mostraron diferencias entre tratamientos $(p>0.05)$.

Tabla 2. Efecto del aditivo con LB-31 en indicadores sanguíneos de los pollos de ceba a los 42 días de edad.

\begin{tabular}{|c|c|c|c|}
\hline \multirow[b]{2}{*}{ Indicador } & \multicolumn{2}{|c|}{ Tratamientos } & \multirow{2}{*}{$\begin{array}{c}\text { 土EE } \\
\text { p-valor }\end{array}$} \\
\hline & Control & $\begin{array}{c}\text { Probiótico } \\
\text { LB-31 }\end{array}$ & \\
\hline Proteínas totales ( $\mathrm{g} / \mathrm{L}$ ) & 29.55 & 28.84 & $\begin{array}{c}1.29 \\
p=0.7029\end{array}$ \\
\hline Albúmina/Globulinas & 0.60 & 0.83 & $\begin{array}{c}0.03 \\
p<0.0001\end{array}$ \\
\hline Albúmina & 1 & 12 & $\begin{array}{c}0.23 \\
p=0.0001\end{array}$ \\
\hline Globulinas (g/L) & 20. & 15.93 & $\begin{array}{c}0.88 \\
p=0.0032\end{array}$ \\
\hline Ácido úrico (mmol/L) & 535.17 & 335.33 & $\begin{array}{c}25.76 \\
p=0.0001\end{array}$ \\
\hline ALAT & 3. & 3.63 & $\begin{array}{c}0.35 \\
p=0.8018\end{array}$ \\
\hline ASAT (u/L) & 22 & 22 & $\begin{array}{c}6.74 \\
p=0.5993\end{array}$ \\
\hline Glucosa (mmol/L) & 11.74 & 12.39 & $\begin{array}{c}0.42 \\
p=0.2943\end{array}$ \\
\hline Amilasa pancrética ( $\mathrm{u} / \mathrm{L})$ & 593.00 & 498.33 & $\begin{array}{c}20.81 \\
p=0.0062\end{array}$ \\
\hline Fosfatasa alcalina (u/L) & 3831.17 & 1762.00 & $\begin{array}{c}193.33 \\
p<0.0001\end{array}$ \\
\hline Colinesterasa (u/L) & 1704.67 & 1972.33 & $\begin{array}{c}46.67 \\
p=0.0012\end{array}$ \\
\hline Glutatión (u/L) & 16.50 & 21.67 & $\begin{array}{c}0.36 \\
p<0.0001\end{array}$ \\
\hline Colesterol (mmol/L) & 3.53 & 3.05 & $\begin{array}{c}0.12 \\
p=0.0152\end{array}$ \\
\hline Triglicéridos (mmol/L) & 1.49 & 1.05 & $\begin{array}{c}0.07 \\
p=0.0004\end{array}$ \\
\hline
\end{tabular}


En la tabla 3 se presentan los resultados de los indicadores morfométricos de los pollos de ceba a los 42 días de edad para los tratamientos estudiados. No se encontraron diferencias para el peso vivo, peso relativo del buche, proventrículo, molleja, hígado, páncreas, ciegos y colon $(p>0.05)$. Sin embargo, el intestino delgado disminuyó $(p<0.05)$ y la grasa abdominal aumentó $(\mathrm{p}<0.05)$ con la inclusión de $L$. pentosus LB-31 en la dieta de los animales.

Tabla 3. Efecto del aditivo con LB-31 en el tracto gastrointestinal y órganos accesorios de los pollos de ceba a los 42 días de edad.

\begin{tabular}{|c|c|c|c|}
\hline \multirow{2}{*}{$\begin{array}{c}\text { Peso relativo } \\
\text { (g/kg peso vivo) }\end{array}$} & \multicolumn{2}{|c|}{ Tratamientos } & \multirow{2}{*}{$\begin{array}{l}\text { p-valor } \\
\text { 土EE }\end{array}$} \\
\hline & Control & $\begin{array}{c}\text { Probiótico } \\
\text { LB-31 }\end{array}$ & \\
\hline Peso vivo (kg) & 2.51 & 2.60 & $\begin{array}{c}0.4299 \\
\pm 0.08\end{array}$ \\
\hline Buche & 5.40 & 6.40 & $\begin{array}{c}0.2895 \\
\pm 0.64\end{array}$ \\
\hline Proventrículo & 4.05 & 4.29 & $\begin{array}{c}0.4261 \\
\pm 0.20\end{array}$ \\
\hline Molleja & 15.31 & 16.51 & $\begin{array}{l}0.1846 \\
\pm 0.61\end{array}$ \\
\hline Intestino delgado & 28.01 & 25.42 & $\begin{array}{c}0.0226 \\
\pm 0.71\end{array}$ \\
\hline Ciegos & 4.36 & 4.00 & $\begin{array}{c}0.4365 \\
\pm 0.31\end{array}$ \\
\hline Colon recto & 2.05 & 2.45 & $\begin{array}{l}0.3117 \\
\pm 0.27\end{array}$ \\
\hline Hígado & 24.09 & 22.90 & $\begin{array}{l}0.5668 \\
\pm 1.43\end{array}$ \\
\hline Páncreas & 2.51 & 2.37 & $\begin{array}{c}0.3847 \\
\pm 0.11\end{array}$ \\
\hline Grasa abdominal & 7.56 & 12.92 & $\begin{array}{c}0.0010 \\
\pm 0.91 \\
\end{array}$ \\
\hline
\end{tabular}

En cuanto a los órganos relacionados con el sistema inmune, LB-31 no tuvo efecto en el peso relativo de la bolsa de Fabricio y el timo. En el primer caso se obtuvieron valores de 2.22 y $2.25 \mathrm{~g} / \mathrm{kg}$ peso vivo ( $E E \pm 0.13 ; \mathrm{p}=0.8523$ ) y en el segundo de 3.30 y $2.81 \mathrm{~g} / \mathrm{kg}$ peso vivo $(\mathrm{EE} \pm 0.31 ; \mathrm{p}=0.2774)$ para el tratamiento control y el probiótico, respectivamente.

\section{DISCUSIÓN}

Los resultados de los indicadores hematológicos (hemoglobina y hematocrito) se encuentran en el intervalo de valores informados por Avilez et al (16) y Gutiérrez y Corredor (17) como normales para pollos de ceba (8.7-10.1 g/dL y $22-35 \%$, respectivamente). Además, son similares a los que obtuvieron García et al (1) al evaluar, en esta misma categoría animal, la cepa $L$. pentosus LB-31 pero cultivada en medio MRS a $37^{\circ} \mathrm{C}$, en condiciones estáticas y 18-24 h de incubación.
Dentro de las proteínas totales, como indicadores del metabolismo proteico, se cuantifican las albúminas y globulinas. La albúmina se sintetiza en el hígado y representa la mayor fracción proteica en las aves. Una baja concentración de esta proteína se asocia con patologías hepáticas y renales. El aumento de la relación albúmina/globulina demuestra que los animales que consumen el probiótico presentaron mayor eficiencia de utilización de la fracción proteica $y$, por ende, mejor estado nutricional. En este sentido, Gutiérrez y Corredor (17) plantearon que los efectos positivos de los probióticos en los procesos digestivos de los pollos se pueden evidenciar a través de indicadores sanguíneos. Por otra parte, la disminución de los niveles de globulinas indicó que no se presentaron procesos infecciosos y que no aumentó la producción de anticuerpos durante el tiempo de consumo del aditivo. Este resultado demuestra que LB31 mejora la modulación del sistema inmune $y$, por tanto, los animales que lo consumieron presentaron mejor estado de salud.

Con respecto al ácido úrico, Hashemzadeh et al (18) obtuvieron resultados similares a los del presente estudio al utilizar, en la dieta de de pollos de ceba, cepas probióticas de Lactobacillus rhamnosus y Berevibacillus laterosporus. Los mismos autores señalaron que el ácido úrico es el producto final del metabolismo de las proteínas (partes de ADN y ARN) y que una disminución en sus niveles de concentración demuestra un efecto positivo del probiótico en la función renal. A su vez, plantearon que algunos microorganismos probióticos pueden utilizar urea, ácido úrico, creatinina y otras toxinas como nutrientes para su crecimiento.

Las enzimas ALAT y ASAT se utilizan para la detección de lesiones hepáticas, obesidad, enfermedades musculares y síndrome metabólico $(19,20)$. El hecho de no detectar diferencias entre tratamientos para cada caso, indica que no existieron estas patologías en los animales, lo que resulta beneficioso para la utilización de LB31 como probiótico en la salud de pollos de ceba.

En relación a los indicadores del metabolismo de carbohidratos, los resultados para la amilasa pancreática señalan que no hubo problemas de inflamación o daños en el páncreas. Mientras que los de glucosa concuerdan con los que informaron Abdel-Hafeez et al (21) y estuvieron en el intervalo normal para pollos de ceba (11.1$22.2 \mathrm{mmol} / \mathrm{L})$, según Díaz et al (22). 
La fosfatasa alcalina es una enzima que se encuentra en casi todos los tejidos del organismo, pero su mayor presencia es en el hígado, las vías biliares y los huesos. Sus altos niveles pueden indicar lesiones hepáticas y óseas. Los estudios de Aluwong et al (23) y Wu et al (24) mostraron resultados similares al presente estudio ya que también obtuvieron disminución de la fosfatasa alcalina con la inclusión, en la dieta de pollos de ceba, de cepas probióticas de levaduras y Lactobacillus plantarum 16, respectivamente. Los autores plantearon que estos resultados indicaron mejoras en la función hepática aunque no describen el mecanismo exacto por el que ocurre este efecto, aspecto en el que se debe profundizar en estudios posteriores.

En la literatura científica consultada, no se encontraron resultados que evidencien el efecto de los probióticos en la colinesterasa de pollos de ceba. No obstante, se conoce que está asociada con dos compuestos que catalizan la hidrólisis del neurotransmisor acetilcolina en colina y ácido acético, reacción necesaria para evitar daños neuronales. De forma general, se pudiera plantear que el aditivo con L. pentosus LB-31 tiene efecto positivo en este indicador, por lo que sería de interés en investigaciones futuras.

El aumento en los niveles de glutatión en los animales que consumieron LB-31, evidencian que el aditivo probiótico pudiera tener capacidad antioxidante al actuar como protector de las células ante el estrés oxidativo. En este sentido, Kullisaar et al (25) demostraron que Lactobacillus fermentum fue capaz de sintetizar glutatión, incluso con un sistema completo de síntesis, absorción y capacidad de rotación redox. Asimismo, Capcarova et al (26) encontraron que cepas probióticas de $L$. fermentum y Enterococcus faecium podrían ser beneficiosas en la resistencia a la oxidación al eliminar radicales libres. Mientras que, Cortez et al (27) y Wu et al (24) evidenciaron la capacidad antioxidante de cepas probióticas de Lactobacillus spp.

En cuanto a los indicadores del metabolismo lipídico, varios autores informaron el efecto hipocolesterolémico de los probióticos. Señalaron que estos aditivos pueden contribuir a la regulación de las concentraciones de colesterol en suero mediante la desconjugación de los ácidos biliares, lo que evita que actúen como precursores en la síntesis de colesterol. Los ácidos biliares desconjugados son menos solubles a $\mathrm{pH}$ bajo y se absorben menos en el intestino y es más probable que se excreten en las heces. Otro mecanismo por el que se puede reducir el colesterol sérico es que los microorganismos probióticos producen ácidos grasos de cadena corta como el ácido propiónico que inhibe la hidroximetil-glutarilcoenzima A reductasa, enzima involucrada en la ruta de síntesis de colesterol $(17,28)$. Por otra parte, Ashayerizadeh et al (28) obtuvieron resultados similares a los del presente estudio para la concentración de triglicéridos cuando suministraron, en la dieta de pollos de ceba, el probiótico comercial Primalac compuesto por una mezcla de cepas de Lactobacillus casei, Lactobacillus acidophilus, Bifidobacterium thermophilum y Enterococcus faecium. Estos autores indicaron que la reducción en el nivel de triglicéridos puede estar relacionada con el aumento de bacterias ácido lácticas en el TGI, ya que estos microorganismos pudieran disminuir la actividad de la acetil coenzima A carboxilasa que limita la velocidad de síntesis de ácidos grasos.

Los microorganismos probióticos cuando se establecen en el tracto gastrointestinal como nicho ecológico, realizan funciones que contribuyen a crear un estado beneficioso para todo el organismo. En este sentido, los resultados que se obtuvieron para el intestino delgado coinciden con los estudios de García et al. (1), quienes plantearon que la disminución en el peso relativo de este órgano pudiera relacionarse con la actividad antimicrobiana de los lactobacilos. Señalaron, además, que esto se debe a que las cepas de Lactobacillus tienen la capacidad de colonizar el TGI, lo que disminuye los sitios de adhesión de bacterias potencialmente patógenas que producen sustancias tóxicas y engrosan la mucosa intestinal. Además, las cepas probióticas pueden producir sustancias antimicrobianas como ácidos orgánicos o bacteriocinas que disminuyen estas poblaciones de bacterias enteropatógenas y de esta forma influir en la reducción del peso del órgano y mejora de la salud intestinal.

Existen resultados diferentes a los que se obtuvieron en el presente estudio con relación al efecto que causan los probióticos en la grasa abdominal de pollos de ceba. Algunos autores como Kalavathy et al (29) y Wang et al (30) afirmaron que los probióticos inciden en la reducción de la grasa abdominal. Estas diferencias pudieran estar asociadas al género o especie de la cepa que se utilice. El aumento en la deposición de la grasa abdominal pudiera deberse a una mayor eficiencia metabólica en 
el uso de la energía. Sin embargo, este es un aspecto que debe comprobarse en estudios posteriores.

La bolsa de Fabricio y el timo son órganos responsables de la inmunidad en las aves. Algunas investigaciones señalan que la adición de probióticos estimula el desarrollo de estos órganos linfoides (31), lo que permite a los animales tener una mejor respuesta inmune frente al ataque de patógenos. Sin embargo, García et al (1) obtuvieron resultados similares a la presente investigación ya que no encontraron efectos en el peso relativo de la bolsa al incluir $L$. pentosus LB-31 (cultivada en MRS) en la dieta de pollos de ceba. Estas diferencias en los resultados se deben, fundamentalmente, a que la acción de los microorganismos probióticos es específica de la especie y cepa que se utilice. También dependen, fundamentalmente, de la dosis de administración, métodos de preparación, edad de los animales, composición de la dieta y estado de higiene $(32,33)$.

De forma general, Aragón et al (34) plantearon que los procesos de obtención de biomasa microbiana deben garantizar que las cepas mantengan sus características probióticas. Los aspectos que más influyen son la composición del medio de cultivo y las condiciones de crecimiento como la velocidad de agitación, $\mathrm{pH}$, temperatura y concentración de oxígeno disuelto. En este sentido, los resultados de los indicadores estudiados ratifican las características probióticas de Lactobacillus pentosus LB-31 que se obtuvieron en estudios anteriores y se demuestra que las nuevas condiciones de cultivo de la cepa no afectaron sus potencialidades.

En conclusión, los resultados del presente estudio permiten plantear que Lactobacillus pentosus LB-31, cultivado en un nuevo medio de cultivo y diferentes condiciones de obtención, mantiene su actividad probiótica en indicadores morfo-fisiológicos y bioquímica sanguínea de pollos de ceba. Resultados que son alentadores para su producción y posterior introducción en los sistemas ganaderos.

\section{Conflicto de intereses}

Los autores declaramos que no existen conflicto de intereses con esta publicación.

\section{Agradecimientos}

Los autores agradecen el trabajo del personal técnico y obrero de la Unidad Central de Laboratorio y el Departamento de Monogástricos del Instituto de Ciencia Animal, Mayabeque, Cuba.

\section{REFERENCIAS}

1. García Y, Pérez T, Boucourt R, Balcázar JL, Nicoli JR, Moreira J et al. Isolation, characterization and evaluation of probiotic lactic acid bacteria for potential use in animal production. Res Vet Sci. 2016; 108:125-132. http://dx.doi.org/10.1016/j. rvsc.2016.08.009

2. FAO/WHO: Food and Agriculture Organization of the United Nations/World Health Organization. London Ontario, Canada. Guidelines for the evaluation of probiotics in food. Report of a joint FAO/WHO working group on drafting guidelines for the evaluation of probiotics in food; 2002. (Fecha de consulta: 25 de octubre de 2019). Disponible en: http://www.who.int/foodsafety/fs management/en/probiotic guidelines.pdf
3. Forssten SD, Sindelar CW, Ouwehand AC. Probiotics from an industrial perspective. Anaerobe. 2011; 17:410-413. http://dx.doi. org/10.1016/j.anaerobe.2011.04.014

4. AlGburi A, Volski A, Cugini C, Walsh EM, Chistyakov VA, Mazanko MS et al. Safety properties and probiotic potential of Bacillus subtilis KATMIRA1933 and Bacillus amyloliquefaciens B-1895. Adv Microbiol. 2016; 6:432-452. http://dx.doi. org/10.4236/aim.2016.66043

5. Vinderola G, Gueimonde M, Gomez-Gallego C, Delfederico L, Salminen S. Correlation between in vitro and in vivo assays in selection of probiotics from traditional species of bacteria. Trends Food Sci Technol. 2017; 68:83-90. http:// dx.doi.org/10.1016/j.tifs.2017.08.005 
6. Nguyen HT, Truong DH, Kouhoundé S, Ly S, Razafindralambo $\mathrm{H}$, Delvigne F. Biochemical engineering approaches for increasing viability and functionality of probiotic bacteria. Int J Mol Sci. 2016; 17:867-884; https://doi.org/10.3390/ijms17060867

7. Bai SP, Wu AM, Ding XM, Lei $Y$, Bai J, Zhang $K Y$ et al. Effects of probiotic-supplemented diets on growth performance and intestinal immune characteristics of broiler chickens. Poult Sci. 2013; 92:663-670. http://dx.doi. org/10.3382/ps.2012-02813

8. Kazemi SA, Ahmadi H, Torshizi MAK. Evaluating two multistrain probiotics on growth performance, intestinal morphology, lipid oxidation and ileal microflora in chickens. J Anim Physiol Anim Nutr. 2019; 103(5):13991407. https://doi.org/10.1111/jpn.13124

9. García Y, Pérez, T. Obtención de microorganismos con actividad probiótica para animales monogástricos. An Acad Cienc Cuba. 2015; 5(3):1-19. http://www. revistaccuba.cu/index.php/revacc/article/ download/225/225

10. Ayala L, García Y, Savón LL, Boucourt R, Castro M, Herrera M. Evaluación de la actividad probiótica del Lactobacillus pentosus en indicadores de salud y productivos de cerditos destetados. Revista Computarizada de Producción Porcina. 2014; 21(3):130133. http://www.iip.co.cu/RCPP/213/213 artLAyala.pdf

11. Gutiérrez González D, García Hernández Y, Sosa Cossio D. El efecto de Lactobacillus pentosus LB-31 como aditivo microbiano en la alimentación de corderos. LRRD 2020; 32(3), Artículo 43. http://www.Irrd.org/ Irrd32/3/yanei32043.html

12. Sosa Cossio D, García Hernández Y, Dustet Mendoza JC. Development of probiotics for animal production. Experiences in Cuba. Cuban J Agri Sci. 2018; 52(4):1-17. https:// www.cjascience.com/index.php/CJAS/ article/view/836/868

13. Nivoliez A, Camares O, Paquet-Gachinat $M$, Bornes S, Forestierc C, Veisseire P. Influence of manufacturing processes on in vitro properties of the probiotic strain Lactobacillus rhamnosus Lcr35 ${ }^{\circledR}$. J Biotechnol. 2012; 160:236-241. http://dx.doi.org/10.1016/j. jbiotec.2012.04.005
14. Crosby WH, Munn JI, Furth FW. Standardizing a method for clinical hemoglobinometry. US Armed Forces Med J. 1954; 5:693-703. https://books.google.com.cu/books?id=KwhAQAAMAAJ\&pg =RA1-PA693\&lpg $=$ RA1PA693\&dq $=$ Standardizing $+a+$ method + fo $\underline{r+c l i n i c a l+h e m o g l o b i n o m e t r y \& s o u r c e}=b \mid$ \&ots $=$ QeZ7qsaNSC\&sig $=$ ACfU3U3Qgb9 uxmBHDZrbaWXbOPGgxHJnA\&hl=es-419\&sa $=$ X\&ved $=2$ ahUKEwjb3I7pxZjaAhWLhOAKHX bsAmQQ6AEwBXoECAoQAQ\# $\mathrm{v}=$ onepage $\& \mathrm{q}=$ Standardizing $\% 20 a \% 20$ method $\% 20$ for $\% 20$ clinical\%20hemoglobinometry\&f=false

15. Di Rienzo JA, Casanoves F, Balzarini MG, Gonzalez L, Tablada M; Robledo CW. InfoStat versión 2012. Grupo InfoStat, FCA, Universidad Nacional de Córdoba: Argentina; 2012 Disponible en: http://www.infostat. com.ar

16. Avilez Colon BL, Rugeles Pinto CC, Jabib Ruiz L, Herrera Benavides YM. Parámetros hematológicos en pollos de engorde criados en una granja de producción cerrada en el trópico bajo. Rev Med Vet. 2015; (29):33-39. http://dx.doi.org/10.19052/mv.3444

17. Gutiérrez Castro LL, Corredor Matus JR. Parámetros sanguíneos y respuesta inmune en pollos de engorde alimentados con probióticos. Vet Zootec. 2017; 11(2):8192. http://vip.ucaldas.edu.co/vetzootec/ downloads/v11n2a07.pdf

18. Hashemzadeh F, Rahimi S, Karimi Torshizi MA, Akbar Masoudi A. Effects of probiotics and antibiotic supplementation on serum biochemistry and intestinal microflora in broiler chicks. Int J Agric Crop Sci. 2013; 5(20):2394-2398. http://ijagcs. com/.../2394-2398.pdf

19. Bustamante V, Arab JP, Terc F, Poggi H, Goycoolea M, Arrese M et al. Aumento aislado y sostenido de aspartato aminotransferasa por presencia de macroenzimas. Caso clínico. Rev Med Chile. 2016; 144:10781082. http://dx.doi.org/10.4067/S0034$\underline{98872016000800017}$

20. Osama R, El-Sanhouty R, Salama A, ElSaman M. In vivo evaluation of local Lactobacillus acidophilus as a probiotics in feed experiment on sprague-dawley rats. Future J Biol. 2020; 1:14-26. http://dx.doi. org/10.37229/fsa.fjb.2020.02.02 
21. Abdel-Hafeez HM, Saleh ESE, Tawfeek SS, Youssef IMI, Abdel-Daim ASA. Effects of probiotic, prebiotic, and synbiotic with and without feed restriction on performance, hematological indices and carcass characteristics of broiler chickens. AsianAustralas J Anim Sci. 2017; 30(5):672-682. https://doi.org/10.5713/ajas.16.0535

22. Díaz López EA, Uribe Velásquez LF, Narvaez Solarte W. Bioquímica sanguínea y concentración plasmática de corticosterona en pollo de engorde bajo estrés calórico. Rev Med Vet. 2014; 28:31-42. https:// ciencia.lasalle.edu.co/cgi/viewcontent. cgi? article $=1197 \&$ context $=$ mv

23. Aluwong $T$, Raji MA, Hassan BF, Kawu MU, Kobo P, Iaand Ayo JO. Effect of different levels of supplemental yeast on performance indices and serum biochemistry of broiler chickens. Open Conf Proc J. 2012; 3:4145. https://dx.doi.org/10.2174/187632 $\underline{6 \times 01203020041}$

24. Wu Y, Wang B, Zeng Z, Liu R, Tang L, Gong $L$ et al. Effects of probiotics Lactobacillus plantarum 16 and Paenibacillus polymyxa 10 on intestinal barrier function, antioxidative capacity, apoptosis, immune response, and biochemical parameters in broilers. Poult Sci. 2019; 98(10):5028-5039. http://dx.doi. org/10.3382/ps/pez226

25. Kullisaar T, Songisepp E, Aunapuu M, Kilk $\mathrm{K}$, Arend A, Mikelsaar $\mathrm{M}$ et al. Complete glutathione system in probiotic Lactobacillus fermentum ME3. Prikl Biokhim Mikrobiol 2010; 46(5):481-486. https://doi.org/10.1134/ $\underline{\text { S0003683810050030 }}$

26. Capcarova M, Weiss J, Hrncar C, Kolesarova A, Pal G. Effect of Lactobacillus fermentum and Enterococcus faecium strains on internal milieu, antioxidant status and body weight of broiler chickens. J Anim Physiol Anim Nutr. 2010; 94:215-224. http://dx.doi. org/10.1111/j.1439-0396.2010.01010.x

27. Cortez R, Meléndez C, Perazzo Y, Márquez Y, Flores C, López Ortega A. Capacidad antioxidante de bacterias con potencial probiótico del género Lactobacillus spp aisladas a partir de heces y contenido duodenal de perros y gatos. Gaceta de Ciencias Veterinarias. 2017; 22(2):48-52. http:// www.ucla.edu.ve/dveterin/departamentos/ CienciasBasicas/gcv/2530int2530er2530no/ articulos/documasp/ 0drtnzir.pdf
28. Ashayerizadeh A, Dabiri N, Mirzadeh $\mathrm{KH}$, Ghorbani, MR. Effect of dietary supplementation of probiotic and prebiotic on growth indices and serum biochemical parameters of broiler chickens. J Cell Anim Biol. 2011; 5(8):152-156. http://citeseerx. ist.psu.edu/viewdoc/download?doi=10.1.1. 893.701\&rep $=$ rep $1 \&$ type $=$ pdf

29. Kalavathy R, Abdullah N, Jalaludin S, Ho YW. Effects of lactobacillus cultures on growth performance, abdominal fat deposition, serum lipids and weight of organs of broiler chickens. Br Poult Sci. 2003; 44:139-144. https://doi. org/10.1080/0007166031000085445

30. Wang $\mathrm{H}$, Ni X, Qing X, Zeng D, Luo M, Liu L et al. Live probiotic Lactobacillus johnsonii BS15 promotes growth performance and lowers fat deposition by improving lipid metabolism, intestinal development, and gut microflora in broilers. Front. Microbiol. 2017; 8:1073. http://dx.doi.org/10.3389/ fmicb.2017.01073

31. Díaz-López EA, Isaza JA, Ángel D. Probióticos en la avicultura: una revisión. Rev Med Vet. 2017; 35:175-179. http://dx.doi. org/10.19052/mv.4400

32. Bai K, Huang Q, Zhang J, He J, Zhang L, Wang T. Supplemental effects of probiotic Bacillus subtilis fmb] on growth performance, antioxidant capacity, and meat quality of broiler chickens. Poult Sci. 2017; 96(1):7482. https://doi.org/10.3382/ps/pew246

33. Zhang ZF, Zhou TX, Ao X, Kim IH. Effects of $\beta$-glucan and Bacillus subtilis, on growth performance, blood profiles, relative organ weight and meat quality in broilers fed maize-soybean meal based diets. Livest Sci. 2012; 150(1-3):419-424. https://doi. org/10.1016/j.livsci.2012.10.003

34. Aragón-Rojas S, Ruiz-Pardo RY, HernándezSánchez H, Quintanilla-Carvajal MX. Optimization of the production and stress resistance of the probiotic Lactobacillus fermentum K73 in a submerged bioreactor using a whey-based culture medium. J Food. 2018; 16(1):1064-1070. https://doi.org/10 $.1080 / 19476337.2018 .1527785$ 